\title{
PENGARUH KOMPETENSI TUTOR, HARGA DAN PRESTASI BELAJAR SISWA TERHADAP LOYALITAS PELANGGAN LEMBAGA BIMBINGAN BELAJAR DENGAN KEPUASAN SEBAGAI VARIABEL INTERVENING
}

\author{
Anastasia Sofie Widyastuti \\ Lembaga Pendidikan Master Privat \\ Sofie.anast@gmail.com \\ Sutrisno \\ Sekolah Tinggi Ilmu Ekonomi Wiyatamandala \\ antonius.sutrisno@yahoo.com
}

\begin{abstract}
Education is an important factor in the development and progress of a nation. The development of the current education sector is marked by the many businesses that are engaged in the field of educational support services (Private Tutoring Institutions). This study aims to find out how the influence of tutor competency, course price level and learning achievement on customer loyalty through satisfaction in the Private Tutoring Institution "Master Privat". The object of the study was the students and parents of Master Private' students as many as 100 respondents. The method of collecting data is by distributing questionnaires. Then the data is analyzed using Path Analysis techniques with software Lisrel version 8.80 and SPSS version 22. The results showed that tutors' competency, price and learning achievement, each had a partial and significant direct effect on satisfaction. Tutor competency, price and learning achievement have a simultaneous effect on satisfaction. And the final result is the competence of the tutor, price and learning achievement influence on customer loyalty through satisfaction as an intervening variable.
\end{abstract}

Keywords: Tutor Competency, Price, Learning Achievement, Satisfaction, and Customer Loyalty

\section{PENDAHULUAN}

Bidang pendidikan saat ini berkembang sangat pesat yang ditandai dengan banyaknya didirikan berbagai institusi pendidikan baik formal maupun non formal. Bisnis dalam bidang pendidikan non formal diantaranya adalah lembaga kursus privat yang memberikan pendampingan belajar pada para siswa sekolah termasuk Lembaga Kursus
"Master Privat" di kota Tangerang Selatan. Banyaknya pesaing di bidang bisnis pendampingan belajar ini membuat Master Privat saat ini mengalami permasalahan rendahnya tingkat pembelian kembali (loyalitas siswa), jumlah siswa yang naik turun setiap bulan karena siswa lama tidak melanjutkan lagi les nya (hanya 1 atau 2 bulan). Walaupun ada pertambahan 
siswa baru setiap bulannya namun siswa lama berkurang. Dari permasalahan ini Master Privat selalu mencari upaya untuk meningkatkan loyalitas pelanggan (siswa) dengan meningkatkan kepuasan mereka. Sesuai teori Kotler \& Armstrong (2017) bahwa pelanggan yang sangat puas biasanya tetap setia untuk waktu yang lebih lama, membeli lagi produk perusahaan dan membicarakan hal-hal yang baik tentang perusahaan dan produknya kepada orang lain, tidak terlalu memperhatikan merek pesaing dan tidak

\section{TINJAUAN PUSTAKA}

Kompetensi Tutor

Kompetensi dimaknai sebagai pemilikan pengetahuan, ketrampilan dan kemampuan yang dituntut sehubungan jabatan seseorang (Djamarah 2017) sedangkan menurut Fahmi (2016) Kompetensi diartikan juga sebagai suatu kemampuan yang dimiliki oleh seorang individu yang memiliki nilai jual dan itu teraplikasi dari hasil kreativitas serta inovasi yang dihasilkan. Menurut Kamus Besar Bahasa Indonesia, tutor adalah orang yang memberi pelajaran (membimbing) kepada seseorang atau sejumlah kecil siswa (di rumah, bukan di sekolah) dan terlalu sensitif terhadap harga. Sebagaimana teori Lovelock \& Wright (2007), menyatakan bahwa manfaat kepuasan pelanggan adalah dapat mendorong pelanggan kembali dan mendorong loyalitas. Dari hasil pengamatan diketahui bahwa faktorfaktor yang diidentifikasi dapat mempengaruhi kepuasan pelanggan (siswa) Master Privat adalah faktor : kompetensi pengajar (tutor), tingkat harga yang bersaing dan prestasi belajar siswa yang meningkat.

menurut Direktorat Pendidikan Masyarakat (2003:4) Tutor adalah tenaga kependidikan pada jalur pendidikan nonformal yang berperan sebagai fasilitator dan motivator dalam membantu pembelajar dan memberikan bimbingan apabila pembelajar menghadapi kesulitan atau masalah pada saat mempelajari bahan atau materi pelajaran. Jadi kompetensi tutor adalah kemampuan, ketrampilan ataupun kecakapan yang dimiliki oleh seorang tutor dalam mengajarkan dan membimbing seorang siswa yang mengalami kesulitan atau masalah pada saat mempelajari bahan atau materi pelajaran. Permendiknas No. 16 tahun 
2007 tentang Standar kualifikasi akademik dan kompetensi guru ditetapkan 4 kompetensi utama yaitu : kompetensi pedagogik, kompetensi kepribadian, kompetensi profeisonal dan kompetensi sosial. Namun untuk penelitian ini hanya digunakan 3 jenis kompetensi untuk tutor yaitu : kepribadian, profesional dan sosial.

\section{Harga}

Harga adalah sejumlah nilai yang diberikan konsumen untuk memperoleh manfaat memiliki atau menggunakan produk atau jasa (Kotler\&Armstrong,2017). Harga adalah segala sesuatu yang harus konsumen berikan untuk mendapatkan produk atau jasa (Masterson \& Pickton, 2014). Harga seringkali digunakan sebagai indikator nilai dimana indikator tersebut dihubungkan dengan manfaat yang dirasakan atas suatu barang dan jasa. Sebagai indikator harga dapat dilihat dari segi keterjangkauan harga oleh konsumen, kesesuaian harga dengan kualitas jasa, daya saing harga dan kesesuaian harga dengan manfaat.

\section{Prestasi Belajar}

Prestasi adalah hasil dari suatu kegiatan yang telah dikerjakan, diciptakan baik secara individual atau kelompok (Djamarah, 2017). Prestasi adalah apa yang telah dapat diciptakan, hasil pekerjaan, hasil yang menyenangkan hati yang diperoleh dengan jalan keuletan kerja. Sedangkan belajar adalah suatu aktivitas yang dilakukan secara sadar untuk mendapatkan sejumlah kesan dari bahan yang telah dipelajari (Djamarah, 2017). Dengan demikian prestasi belajar dapat diartikan yaitu hasil yang diperoleh berupa kesankesan yang mengakibatkan perubahan dalam diri individu sebagai hasil dari aktivitas dalam belajar. Menurut Arini (2012) prestasi adalah hasil belajar dimana seseorang telah mengikuti proses kegiatan belajar yang dinyatakan dengan nilai atau skor. Toshiana (2012) mengatakan prestasi belajar sering dipakai untuk menentukan kelulusan atau keberhasilan siswa. Winkel (2007) mengungkapkan bahwa prestasi belajar adalah bukti keberhasilan belajar atau hasil kemampuan siswa dalam kegiatan belajarnya sesuai dengan bobot yang dicapainya. Bobot yang dimaksud adalah nilai siswa yang dapat dilihat atau dinyatakan dalam bentuk rapor, indeks prestasi studi, angka kelulusan dan predikat keberhasilan (Gunadi \& Gunawan,2014). 
Kepuasan

Zeithaml dan Bitner dalam Sangadji (2013:180) kepuasan konsumen merupakan “customer's evaluation of a product or service in terms of whether that product or service has met their needs and expectation". (Kepuasan merupakan evaluasi konsumen terhadap produk atau jasa apakah produk atau jasa tersebut telah memenuhi kebutuhan dan pengharapannya). Pelanggan yang sangat puas biasanya tetap setia untuk waktu yang lebih lama, membeli lagi produk perusahaan dan membicarakan hal-hal yang baik tentang perusahaan dan produknya kepada orang lain, tidak terlalu memperhatikan merek pesaing dan tidak terlalu sensitif terhadap harga. Loyalitas

\section{METODE PENELITIAN}

Metode penelitian yang digunakan dalam penelitian ini adalah metode deskriptif dan verifikatif. Sumber data penelitian diperoleh dari sumber data primer (dari hasil wawancara dan menyebar kuesioner kepada responden yang merupakan siswa dan eks siswa Master Privat) dan data sekunder (yaitu dari telaah pustaka/literatur dari bukubuku, jurnal penelitian sebelumnya dan
Pelanggan yang loyal bagi sebuah perusahaan dapat menjadi sumber pendapatan yang terus menerus dalam kurun waktu yang lama sehingga memberikan keuntungan bagi perusahaan. Konsumen yang loyal merupakan asset penting bagi perusahaan. Griffin dalam Sangadji (2013:105) menyatakan bahwa konsumen yang loyal memiliki karakteristik yaitu: melakukan pembelian secara teratur, melakukan pembelian di semua lini produk atau jasa, merekomendasikan produk kepada pihak lain, dan menunjukkan kekebalan dari daya tarik produk sejenis dari pesaing.

artikel di internet). Sebagai populasi adalah seluruh siswa dan eks siswa Master Privat dari awal tahun 2014 sampai dengan Desember 2018 berjumlah 108 orang. Metode pengambilan sampel adalah dengan metode sensus dimana seluruh elemen populasi juga merupakan subjek sampel karena jumlah populasi masih dapat diukur (finite). Namun dalam penelitian ini sampel ditetapkan sebanyak 100 
responden. Teknik analisa data mengetahui apakah kuesioner yang menggunakan Analisis Jalur (Path digunakan benar-benar valid untuk Analysis) dengan bantuan software mengukur variabel yang diteliti, Uji Lisrel versi 8,80 untuk mengetahui reliabilitas untuk mengetahui adanya pengaruh langsung dan signifikansi variabel kompetensi tutor, harga dan prestasi belajar siswa terhadap kepuasan dan pengaruh langsung dan signifikansi masingmasing variabel tersebut terhadap loyalitas siswa dengan kepuasan sebagai variabel perantara (intervening). Sebelumnya dilakukan Uji Validitas dengan Korelasi Bivariate Pearson menggunakan SPSS versi 22 untuk konsistensi data yang sudah diuji validitasnya dengan menggunakan metode Cronbach Alpha SPSS 22, Uji Multikolinearitas untuk menguji apakah diantara variabel bebas saling berkorelasi yaitu dengan menggunakan nilai Tolerance dan VIF (Varian Inflation Factor) dan Uji Normalitas untuk memastikan data berdistribusi normal yaitu dengan menggunakan metode Kolmogorov Smirnoff.

Gambar 1 Model Penelitian

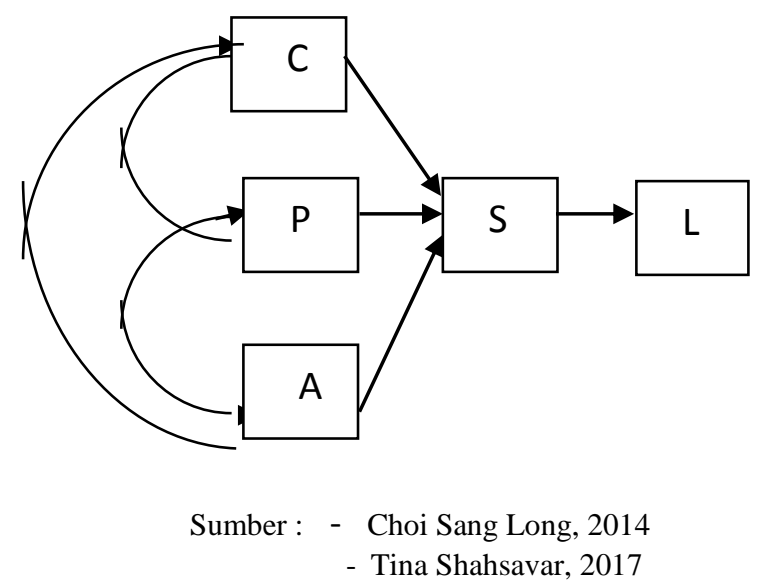

Keterangan :
C : Kompetensi Tutor $\left(\mathrm{X}_{1}\right)$
$\mathrm{P}$ : Harga $\left(\mathrm{X}_{2}\right)$
A : Prestasi Belajar $\left(\mathrm{X}_{3}\right)$
$\mathrm{S} \quad$ : Kepuasan $\left(\mathrm{Y}_{1}\right)$
$\mathrm{L} \quad$ : Loyalitas $\left(\mathrm{Y}_{2}\right)$ 


\section{HASIL DAN PEMBAHASAN}

\section{Gambar 2 Model Analisis Jalur}

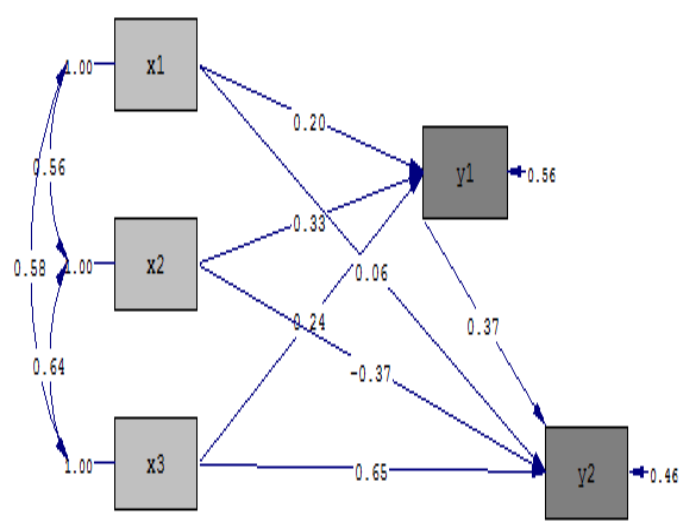

Dari hasil analisa menggunakan analisis jalur (path snalysis) diketahui bahwa model penelitian dapat diterima. Selanjutnya berdasarkan model fit tersebut dilakukan pengujian 5 hipotesis yang diajukan dalam penelitian ini.

Hipotesis 1 : Kompetensi Tutor berpengaruh terhadap kepuasan

Terdapat pengaruh parsial, langsung dan signifikan kompetensi tutor terhadap kepuasan siswa yang ditunjukkan dengan nilai koefisien jalur (p) sebesar 0,20 (20\%). Keputusan uji hipotesis 1 adalah $\mathrm{H}_{0}$ ditolak dan $\mathrm{H}_{1}$ diterima yang berarti bahwa kompetensi seorang pengajar/tutor berpengaruh terhadap kepuasan siswa.
Hipotesis 2 : Harga berpengaruh terhadap kepuasan

Terdapat pengaruh parsial, langsung dan signifikan harga kursus terhadap kepuasan siswa yang ditunjukkan dengan nilai koefisien jalur (p) sebesar $0,33(33 \%)$. Keputusan uji hipotesis 2 adalah $\mathrm{H}_{0}$ ditolak dan $\mathrm{H}_{2}$ diterima yang berarti bahwa harga kursus berpengaruh terhadap kepuasan siswa.

Hipotesis 3 : Prestasi Belajar berpengaruh terhadap kepuasan

Terdapat pengaruh parsial, langsung dan signifikan prestasi belajar siswa terhadap kepuasan siswa dengan nilai koefisien jalur sebesar 0,24 (24\%). Keputusan uji hipotesis 3 adalah $\mathrm{H}_{0}$ ditolak dan $\mathrm{H}_{3}$ diterima yang berarti 
bahwa prestasi belajar berpengaruh terhadap kepuasan siswa. Adanya peningkatan prestasi berpengaruh cukup besar terhadap kepuasan siswa.

Hipotesis 4 : Kompetensi Tutor, Harga dan Prestasi belajar berpengaruh secara simultan terhadap kepuasan

Terdapat pengaruh kompetensi tutor, harga dan prestasi belajar secara simultan terhadap kepuasan siswa dengan nilai SMC (Squared Multiple Correlation) atau R2 sebesar 0,44 (44\%). Jika secara parsial masingmasing variabel bebas ini hanya memberikan pengaruh langsung yang tidak terlalu besar terhadap kepuasan namun jika dilihat secara bersama-sama (simultan) maka pengaruhnya meningkat cukup besar. Dengan demikian hasil uji hipotesis 4 ini adalah $\mathrm{H}_{0}$ ditolak dan $\mathrm{H}_{4}$ diterima yang berarti ada pengaruh kompetensi tutor, harga dan prestasi belajar secara simultan terhadap kepuasan siswa.

Hipotesis 5 : Kompetensi Tutor, Harga dan Prestasi Belajar berpengaruh terhadap Loyalitas melalui Kepuasan sebagai variabel intervening

Terdapat pengaruh kompetensi tutor, harga dan prestasi belajar terhadap loyalitas siswa dengan kepuasan sebagai variabel intervening dengan nilai SMC (Squared Multiple Correlation) atau $\mathrm{R}^{2}$ sebesar 0,54 (54\%). Hal ini menunjukkan bahwa kepuasan berpengaruh cukup signifikan sebagai variabel perantara. Jika tanpa melalui variabel kepuasan sebagai perantara maka pengaruh kompetensi tutor, harga dan prestasi terhadap loyalitas hanya sebesar 0,46 (46\%). Kesimpulan uji hipotesis 5 adalah $\mathrm{H}_{0}$ ditolak dan $\mathrm{H}_{5}$ diterima yang berarti bahwa ada pengaruh variabel kepuasan sebagai variabel intervening bagi kompetensi tutor, harga dan prestasi terhadap loyalitas siswa.

Berdasarkan hasil olah data dan uji hipotesis tersebut dapat disimpulkan sebagai berikut:

1. Terdapat pengaruh langsung dan signifikan kompetensi tutor terhadap kepuasan siswa sebesar $20 \%$. Walaupun pengaruh saat ini tidak terlalu besar namun dapat dikatakan kompetensi tutor Master Privat cukup memberikan kontribusi bagi kepuasan siswa. Kompetensi kepribadian cukup besar memberikan pengaruh bagi 
kepuasan dengan mean score 4,36 dan 4,28. Sebagian besar responden setuju dengan pernyataan "tutor berkepribadian baik" dan "pendekatan dan interaksi dengan siswa baik". Sedangkan mean score terendah $(3,90)$ pada pernyataan "tutor kurang dapat memotivasi siswa untuk giat belajar dan berprestasi" sehingga meskipun terdapat pengaruh kompetensi sebesar 20\% namun perlu ada peningkatan kompetensi lainnya agar pengaruhnya terhadap kepuasan dapat lebih besar.

2. Terdapat pengaruh langsung dan signifikan harga kursus terhadap kepuasan sebesar 33\%. Faktor harga berpengaruh dominan terhadap kepuasan siswa dibanding 2 faktor lainnya. Faktor harga adalah pertimbangan pertama dan utama bagi orangtua siswa dalam memutuskan apakah akan memilih kursus di Master Privat. Saat ini sebagian besar responden setuju dengan pernyataan "harga kursus Master Privat sesuai dengan kualitas pengajaran yang diberikan" dan harga kursus Master Privat terjangkau namun juga menyatakan bahwa harga relatif tidak murah. Walaupun begitu siswa tetap kursus di Master Privat karena dirasakan harga sesuai perkiraan mereka dan sesuai dengan kualitas yang didapat.

3. Terdapat pengaruh langsung dan signifikan prestasi belajar terhadap kepuasan siswa sebesar $24 \%$. Adanya peningkatan dan kemajuan dalam prestasi belajar siswa adalah faktor penting kedua yang mendominasi kepuasan siswa. Sesuai dengan tujuan orangtua siswa memberi kursus anaknya agar ada perkembangan pada prestasi belajar anaknya. Hal ini sesuai dengan temuan sebagian besar responden setuju dengan pernyataan bahwa "nilai tes harian mengalami peningkatan dibandingkan waktu sebelum kursus pada Master Privat" (mean score tertinggi yaitu 3,85). Peningkatan nilai test harian adalah efek langsung dari pendampingan belajar oleh tutor. Jika siswa sudah lebih 
mengerti materi maka

diharapkan dalam test mid semester dan akhir semester nilainya juga dapat meningkat.

4. Terdapat pengaruh secara simultan dan signifikan kompetensi tutor, harga dan prestasi belajar terhadap kepuasan siswa sebesar $44 \%$. Berarti terdapat peningkatan pengaruh jika ketiga variabel bebas ini dilihat secara bersamasama. Dapat disimpulkan jika manajemen ingin meningkatkan kepuasan maka harus memperhatikan dan mengatur ketiga variabel tersebut karena saling berpengaruh dalam penentuan kepuasan

5. Terdapat pengaruh kompetensi tutor, harga dan prestasi belajar terhadap loyalitas siswa melalui kepuasan sebagai variabel intervening sebesar 54\%. (SMC atau R2 = 0,54) Dibanding jika tanpa melalui kepuasan, maka ketiga variabel bebas hanya akan berpengaruh terhadap loyalitas sebesar $46 \%$ (SMC atau $\mathrm{R}^{2}=$ 0,46). Hal ini berarti bahwa siswa akan loyal jika mereka mengalami kepuasan terlebih dahulu. Jadi jika ingin menaikkan tingkat loyalitas siswa maka harus memfokuskan pada bagaimana cara-caranya agar siswa/konsumen bisa merasa lebih puas lagi. Perbaikan dan peningkatan masing-masing variabel bebas dilakukan secara berkesinambungan (misalnya kompetensi tutor lebih ditingkatkan, harga ditinjau secara berkala dan prestasi siswa dipantau secara rutin). 
Tabel 1 Hasil Rangkuman Koefiesn Jalur

\begin{tabular}{|c|c|c|c|c|}
\hline Pengaruh & $\begin{array}{r}\text { Koefisien } \\
\operatorname{Jalur}(p)\end{array}$ & $\begin{array}{l}\text { SMC } \\
\left(\mathbf{R}^{2}\right)\end{array}$ & Keterangan & Kesimpulan \\
\hline $\mathrm{X}_{1 \rightarrow \mathrm{Y}_{1}}$ & $\begin{array}{c}0.20 \\
(20 \%)\end{array}$ & - & $\begin{array}{l}\text { Ada pengaruh parsial } \\
\qquad \mathrm{X}_{1} \rightarrow \mathrm{Y}_{1}\end{array}$ & $\begin{array}{l}\mathrm{H}_{0} \text { ditolak } \\
\mathrm{H}_{1} \text { diterima }\end{array}$ \\
\hline $\mathrm{X}_{2} \rightarrow \mathrm{Y}_{1}$ & $\begin{array}{c}0.33 \\
(33 \%)\end{array}$ & - & $\begin{array}{l}\text { Ada pengaruh parsial } \\
\qquad \mathrm{X}_{2} \rightarrow \mathrm{Y}_{1}\end{array}$ & $\begin{array}{l}\mathrm{H}_{0} \text { ditolak, } \mathrm{H}_{2} \\
\text { diterima }\end{array}$ \\
\hline $\mathrm{X}_{3} \rightarrow \mathrm{Y}_{1}$ & $\begin{array}{l}0.24 \\
(24 \%)\end{array}$ & - & $\begin{array}{l}\text { Ada pengaruh parsial } \\
\qquad \mathrm{X}_{3} \rightarrow \mathrm{Y}_{1}\end{array}$ & $\begin{array}{l}\mathrm{H}_{0} \text { ditolak, } \mathrm{H}_{3} \\
\text { diterima }\end{array}$ \\
\hline $\mathrm{X}_{1}, \mathrm{X}_{2}, \mathrm{X}_{3} \rightarrow \mathrm{Y}_{1}$ & - & $\begin{array}{c}0.44 \\
(44 \%\end{array}$ & $\begin{array}{l}\text { Ada pengaruh } \\
\qquad \begin{array}{l}\text { simultan } \\
\mathrm{X}_{1}, \mathrm{X}_{2}, \mathrm{X}_{3} \rightarrow \\
\mathrm{Y}_{1}\end{array}\end{array}$ & $\begin{array}{l}\mathrm{H}_{0} \text { ditolak, } \mathrm{H}_{4} \\
\text { diterima }\end{array}$ \\
\hline $\mathrm{Y}_{1} \rightarrow \mathrm{Y}_{2}$ & $\begin{array}{c}0.37 \\
(37 \%)\end{array}$ & - & $\begin{array}{c}\text { Ada pengaruh } \\
\mathrm{Y}_{2}\end{array}$ & - \\
\hline$\underset{\mathrm{X}_{1}, \mathrm{X}_{2}, \mathrm{X}_{3}, \rightarrow \mathrm{Y}_{2} \text { melalui }}{\mathrm{Y}_{1}}$ & - & $\begin{array}{c}0.54 \\
(54 \%\end{array}$ & $\begin{array}{l}\text { Ada pengaruh } \\
\qquad \begin{array}{l}\mathrm{X}_{1}, \mathrm{X}_{2}, \mathrm{X}_{3} \\
\text { terhadap } \mathrm{Y}_{2} \\
\text { dengan } \mathrm{Y}_{1} \\
\text { sebagai } \\
\text { variabel } \\
\text { intervening }\end{array}\end{array}$ & $\begin{array}{l}\mathrm{H}_{0} \text { ditolak, } \mathrm{H}_{5} \\
\text { diterima }\end{array}$ \\
\hline
\end{tabular}

\section{SIMPULAN DAN SARAN}

Dari uraian hasil analisa data tersebut diatas, dugaan/hipotesis bahwa variabel-variabel kompetensi tutor, harga dan prestasi belajar berpengaruh terhadap kepuasan telah teruji kebenarannya. Dugaan/hipotesis bahwa variabel kompetensi tutor, harga dan prestasi belajar berpengaruh terhadap loyalitas siswa melalui kepuasan sebagai variabel intervening juga telah teruji kebenarannya. Terbukti jika melalui kepuasan sebagai perantara maka didapat hasil pengaruh terhadap loyalitas lebih besar jika dibanding tanpa melalui kepuasan.

Bagi pihak lembaga Master Privat dapat melakukan beberapa hal untuk peningkatan kepuasan siswa dengan cara antara lain :

a. Melakukan review dan penilaian kinerja tutor secara berkala dengan berbagai metode penilaian.

b. Untuk menghindari kesalahan dalam memilih tutor dilakukan peningkatan teknik seleksi dan rekrutmen.

c. Tutor dapat lebih memotivasi 
siswa (misal dengan pemberian reward, dll)

d. Survey secara berkala harga kursus privat ke beberapa pesaing sebagai masukan dan bahan perbandingan.

e. Memberikan promosi-promosi khusus (misal : free sesion atau free trial) sebagai pelengkap harga kursus (benefit tambahan) sehingga harga kursus tidak terkesan mahal karena banyak keuanggulan lain yang ditawarkan

f. Menjaga hubungan baik dengan tutor dan orangtua siswa.

g. Cepat tanggap dan responsif terhadap keluhan pelanggan untuk meningkatkan kepuasan yang

\section{DAFTAR PUSTAKA}

Adiputra, Sofwan dan Mujiyati. 2017. Motivasi dan Prestasi Belajar Siswa di Indonesia : Kajian Meta Analisis. Jurnal Konselor Vol. 6 No. 4. ISSN : 1412-9760.

Djamarah, Syaiful Bahri. 2017. Prestasi Belajar dan Kompetensi Guru, Surabaya : Usaha Nasional.

Fahmi, Irham. 2016. Pengantar Manajemen Sumber Daya Manusia Konsep dan Kinerja. Cetakan Pertama. Jakarta : Mitra Wacana Media.

Gunadi, Chintia Leo dan William Gunawan. 2014. Hubungan motivasi akademik dengan dapat berujung pada loyalitas.

Penelitian lanjutan dan pengujian variabel-variabel kompetensi tutor, harga dan prestasi belajar dapat dilakukan dengan menggunakan metodologi lain untuk menganalisa lebih dalam hal-hal yang ingin diketahui perusahaan. Variabel independen lain yang tidak diteliti dalam penelitian ini, yang dapat mempengaruhi kepuasan dan loyalitas dapat ditambahkan seperti kualitas layanan, strategi pemasaran, brand image dan lain-lain.

Prestasi Belajar Siswa SMA X di Jakarta Barat.

Juanim. 2016. Analisis Jalur dalam

Riset Pemasaran e-book, Bandung : FE Universitas Pasundan Jurnal NOETIC Psychology Vol. 4 No. 1. ISSN : 2088-0359

Kotler, Philip dan Kevin Lane Keller. 2015. Manajemen Pemasaran Edisi ke-13. Jakarta : Erlangga 
Kotler, Philip dan Gary Armstrong. 2017. Marketing An

California : SAGE Publication

Introduction, 13th edition, Ltd. England : Pearson Education Limited.

Lovelock, Christopher H dan Lauren K. Wright. 2007. Manajemen Pemasaran Jasa. Jakarta : PT. Indeks

Masterson, Rosalind dan David Pickton. 2014. Marketing An Introduction 3rd edition.

Sugiarto, Tonny Hendratono, Djoko Sudibyo. 2015. Metodologi Penelitian Hospitaliti \& Pariwisata. Tangerang : PT. Matana Publishing Utama 